\title{
IMPACTS OF $\mathrm{CO}_{2}$ TAXES IN AN ECONOMY WITH NICHE MARKETS AND LEARNING-BY-DOING
}

\author{
R. Gerlagh, R. (IVM) \\ B.C.C.. van der Zwaan (ECN and Harvard University) \\ M.W. Hofkes (IVM) \\ G. Klaassen (IIASA)
}

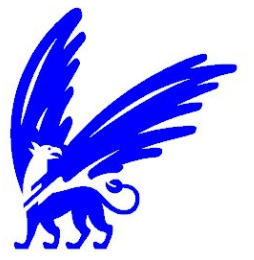

vrije Universiteit amsterdam / IVM 


\title{
Acknowledgement
}

This study, performed with the DEMETER model, is a contribution of ECN (Policy Studies Department) and IVM (Vrije Universiteit Amsterdam) to the EU funded NEMESIS-ETC project, known at ECN as ETC (Endogenous Technological Change) under project number 7.7473. The authors at IVM thank the Netherlands Organisation for Scientific Research (NWO) for financial support. Bob van der Zwaan thanks CISAC, Stanford University, for the freedom enjoyed to use part of his time to undertake research with DEMETER. We thank IIASA, for making available previous innovative work on learning-by-doing, used for the development of the DEMETER model.

\begin{abstract}
In this paper, we analyse the impact of carbon taxes on emission levels, when niche markets exist for new carbon-free technologies, and when these technologies experience 'learning-bydoing' effects. For this purpose, a general equilibrium model has been developed, DEMETER, which specifies two energy technologies: one based on fossil fuels and one on a composite of carbon-free energy technologies. Initially, the carbon-free technology has relatively high production costs, but niche markets ensure positive demand. Learning-by-doing decreases production costs, which increases the market share, which in turn accelerates learning-by-doing, and so forth. This mechanism allows a relatively modest carbon tax, of about $50 \mathrm{US} \$ / \mathrm{tC}$, to almost stabilise carbon emissions at their 2000 levels throughout the entire $21^{\text {st }}$ century. Sensitivity analysis shows that the required carbon tax for emission stabilisation crucially depends on the elasticity of substitution between the fossil fuel and carbon-free technology.
\end{abstract}

Keywords: energy, carbon taxes, endogenous technological change, niche markets. JEL classification: H21, D58, C61, O33, Q40. 


\section{CONTENTS}

LIST OF FIGURES 4

1. INTRODUCTION 5

2. MODEL SPECIFICATION FOR DEMETER 9

2.1 The representative consumer 10

2.2 The final good producer 10

$\begin{array}{lll}2.3 & \text { Energy producers } & 11\end{array}$

$\begin{array}{lll}2.4 & \text { Technological change } & 12\end{array}$

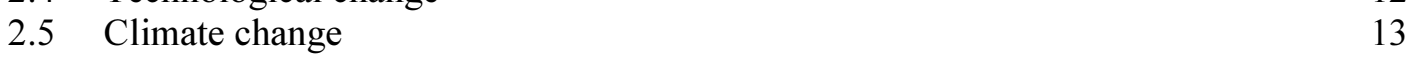

3. CALIBRATION AND DATA FOR NUMERICAL ANALYSIS 14

$\begin{array}{lll}3.1 & \text { Volumes } & 14\end{array}$

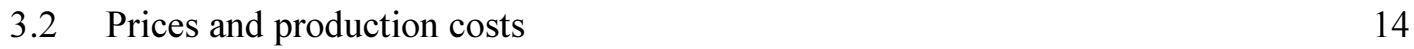

4. SIMULATION RESULTS 17

5. CONCLUSIONS 21

REFERENCES 22

APPENDIX $1 \quad$ FIRST ORDER CONDITIONS FOR PROFIT MAXIMIZATION 25

APPENDIX 2 FULL SPECIFICATION OF EQUILIBRIUM EQUATIONS AND $\begin{array}{ll}\text { VARIABLES } & 27\end{array}$ 


\section{LIST OF FIGURES}

Figure 2.1 DEMETER schematic overview of flows 9

Figure 4.1 Carbon emissions for BaU and different constant carbon tax levels, $\sigma=3 \quad 17$

Figure 4.2 Non-carbon energy share for BaU and 50\$/tC carbon tax and different $\sigma \quad 19$

Figure 4.3 Carbon emissions for BaU and 50\$/tC carbon tax and different $\sigma \quad 20$

Figure 4.4 Global average atmospheric temperature change, relative to pre-industrial levels, for BaU and 50\$/tC carbon tax and different $\sigma$ 


\section{INTRODUCTION}

The recognition that anthropogenic emissions of greenhouse gases may cause global change of climatic conditions has led to the development of Integrated Assessment Models (IAMs). These models integrate the simulation of climate change dynamics with the modelling of the economic system. In most IAMs, future emission reduction costs are approximately independent of measures taken today, that is, emission reduction cost functions are separable over time. Often, costcurves are calculated with computable general equilibrium (CGE) models based on some exogenously assumed path describing technological development (see e.g. Dasgupta and Heal, 1979; Boyd and Uri, 1991; Jorgenson and Wilcoxen, 1993a, 1993b). Although in these models present-day policies affect future allocations and future costs of emission reductions through the investments made in physical man-made capital, the forward connection is limited as a result of the depreciation of capital. The modelling of endogenous technological change, however, leads to the phenomenon that the implementation of emission reductions at present enhances technological development and thus reduces reduction costs in the future (Carraro and Galeotti, 1997; Goulder and Matthai, 2000; van der Zwaan et al., 2002; Buonanno et al., 2003, Gerlagh and van der Zwaan, 2003). ${ }^{1}$ This implies that a stronger relationship exists between the costs of future abatement technologies and today's emission reduction measures.

Since a major part of carbon emissions are linked to energy use, two major options are available for its reduction. First, energy use can be reduced, and, second, energy production can be transformed from the use of fossil-fuel technologies to that of energy technologies that have zero or low net carbon emissions. In addition, carbon dioxide can be removed, or scrubbed. Since energy is essential for economic production, the first option to reduce emissions can be realized to a limited extent only. If substantial emission reductions are aimed for, the transition towards carbon-free technologies is necessary. However, making such a significant transition to new technologies takes a possibly huge amount of time. After a technology becomes competitive, it enters the market through diffusion, and this requires the development of new vintages of products (capital) in which that technology is used. Diffusion often requires a time scale several times the lifetime of such products (Knapp, 1999). As the technology option needs time for implementation, energy demand reduction is likely to prove more useful for short-term emission reductions. Energy demand reduction measures, however, are likely to produce only moderate effect. A shift to carbon-free technologies may, in the long run, prove an option to reach more ambitious reduction levels.

If a transition to carbon-free energy technologies is to become successful, production costs need to decrease, in order to make the new technologies competitive with the existing fossil fuel based technologies. There is clear empirical evidence that the development of production costs for energy based on new technologies depends on cumulative experiences (McDonald and Schrattenholzer, 2001), and is thus an endogenous process.

Today, the dynamics of endogenous technological progress receives an increasing attention in the literature. Messner $(1995,1997)$ includes technological progress in the system-engineering model MESSAGE. In her analysis, costs of specific technologies are explicitly linked to the cumulative capacity installed, reflecting the notion of a learning curve: the costs of specific energy technologies decrease as investments and installed capacities accumulate. In an energy production costs minimisation programme, Messner finds that the inclusion of endogenous technological progress leads generally to earlier investments in new technologies and a lower level of overall (discounted) investments, in comparison to the case in which technological pro-

\footnotetext{
1 For a broader coverage of endogenous technological change and environmental pressure, see also Gradus and Smulders 1993; Bovenberg and Smulders 1995; den Butter and Hofkes 1995; Verdier 1995; Bovenberg and Smulders 1996; Hofkes 1996; Beltratti 1997, Newell et al. 1999; Smulders 1999; Goulder and Matthai 2000.
} 
gress is represented exogenously. Grübler and Messner (1998) link the MESSAGE model to a carbon cycle model to address the question of the optimal timing of $\mathrm{CO}_{2}$ abatement. Their findings suggest that the treatment of technological progress as an endogenous process implies an (optimal) emission trajectory with higher emission reductions in the near term. Both 'bottomup' analyses tend to produce the typical pattern of a discrete and complete switch towards a new technology once it becomes competitive (Odell, 1999). Explicit constraints on market shares and penetration rates avoid such an unrealistic pattern. However, these constraints - if binding determine much of the results, and call for further explanation.

Work by van der Zwaan et al. (2002) and Gerlagh and van der Zwaan (2003) incorporates the learning curve in a macro-economic model, DEMETER (DEcarbonisation Model with Endogenous Technologies for Emission Reductions), that endogenously describes the diffusion process through aggregate production functions with elastic demand for energy produced by specific technologies. ${ }^{2}$ Qualitatively, van der Zwaan et al. (2002) and Gerlagh and van der Zwaan (2003) find similar results as Grübler and Messner (1998). The forward shift in emission reductions in their simulation turns out to be more articulated, however. Nordhaus (2002) incorporates induced innovation through R\&D (as opposed to learning-by-doing) in an up-dated version of his DICE model. In this so-called R\&DICE model, a rise in the price of carbon energy induces firms to develop new processes and products that are less carbon-intensive than existing products. Nordhaus concludes that endogenous technological change is a less powerful factor influencing climate change policy than substitution of capital and labour for energy. Goulder and Mathai (2000) incorporate induced technological progress as a function of R\&D expenditures, as well as in the form of learning-by-doing. In their R\&D model, the future costs of abatement decrease through investments in knowledge, but are independent of past abatement levels. Consequently, the availability of cheaper future abatement measures reduces the need for current abatement. In their learning-by-doing model, knowledge is gained by past abatement, and this justifies early abatement efforts, if the aim is cost-efficiency at least.

The literature is generally silent when it comes to addressing a number of market conditions and features such as the existence of niche markets that can support the development of new technologies. Since most innovations are not immediately cost-effective, niche markets generating positive demand for relatively expensive technologies are a vital phase of technological development (Grübler et al., 1999a, 1999b). Niche markets advance diffusion through accelerating learning-by-doing, and thereby help new technologies to mature. Niche markets help us to avoid technological 'lock-ins', e.g. by widening the attainable set of future technologies. In an analysis of technological development and uncertainty, Grübler and Messner (1998) explain the presence of niche markets as a hedging strategy consisting of R\&D and experimentation. Firms invest in a diverse technology spectrum to secure their future position in an uncertain future market. Still, there are also other economic mechanisms on the user's side that explain the presence of niche markets, such as technology characteristics that are advantageous for specific user groups. For example, electricity production from solar photovoltaic cells proves competitive in some remote areas such as small islands. Government subsidies can be used to expand niche markets enhancing the diffusion of new technologies. The models used by Knapp (1999) and Grübler and Messner (1998) are rich in technological detail, but have limited capability for describing the economic interaction between production, prices and demand, which are all essential parts of a maturing technology.

IAMs that include both production and demand of energy are better equipped to include some of these interactions in an appropriate manner. There is still room to improve their performance, especially in as far as it concerns their description of niche markets. In some models (e.g. Peck

\footnotetext{
2 Note that in the current version of DEMETER there is only endogenous technical change in the energy sector, while no endogenous technical change is simulated in the production of the (final) consumption good. Buonanno et al. (2001) and Buonanno et al. (2003) have studied endogenous (induced) technical change in the final goods sector.
} 
and Teisberg 1992), carbon-free technologies are considered perfect substitutes for fossil-fuel technologies, but have limited maximum supply and relatively high production costs that do not decrease over time. Such a set of assumptions does not facilitate an explanatory description of niche markets, since under perfect substitution demand is zero for all but the cheapest technology, unless positive demand is explicitly included as a volume constraint. More generally, perfect substitution between different technologies cannot explain that relatively expensive new technologies can develop before they become fully competitive with mature technologies. In contrast, other models assume complementarity between energy technologies. In Stephan et al. (1997) and Goulder and Schneider (1999), carbon-free technologies and fossil fuel based technologies are relatively poor substitutes, that is, they have a substitution elasticity of unity, or less $^{3}$. Under this assumption, carbon-free technologies will not reach a substantial market share, irrespective of future decreases in production costs.

This paper differs from the literature, because we do not search for efficient or cost-effective reduction scenarios. Instead, we go back one step to the fundamentals of the global warming problem, and study the energy demand and transition dynamics of the energy system in relation to the substitution possibilities between fossil fuel based and carbon-free energy technologies. As an alternative to both extreme assumptions encountered in the literature, that is those of perfect substitution and complementarity (that is, poor substitutability), we assume good but imperfect substitutability between different energy technologies. More precisely, we suggest the elasticity of substitution has a value larger than unity (representing good substitutability), while still being finite (that is, there is no perfect substitutability). By avoiding elasticities of substitution smaller than or equal to one, we do not consider cases where poor substitutability prevails. However, by using a CES (Constant Elasticity of Substitution) aggregate for various energy sources, in a methodological perspective we do not deviate from the literature: the implications of our choice for the elasticity level between unity and infinity are still substantial. The elasticity level predicts a small but positive market share for new expensive technologies, and a rapidly increasing share when production costs decrease. Thus, DEMETER enables us to model niche markets for new technologies and increasing markets for maturing technologies that gradually become competitive, without needing to describe exogenous penetration paths for new technologies as is common in many other studies.

We present calculations with DEMETER, a relatively simple general equilibrium model incorporating a rudimentary climate change simulation. Basically, the same model has been used in van der Zwaan et al. (2002) and Gerlagh and van der Zwaan (2003), though in these two studies somewhat different scenarios were considered compared to this paper. The different subjects of these three papers (the timing effects of endogenising technological change in the 2002 paper, the cost impacts of endogenous technological change in the 2003 paper, and the role of the simulation of niche markets in the present paper) gave rise to somewhat different usages of DEMETER, to fit, respectively, the question under consideration in each of these papers. Also, a number of slight differences occur because of new energy data that have been used for model calibration. But otherwise, no major modelling variations have been employed, the analysis presented in this article thus having been performed with the same DEMETER version as described in the two earlier DEMETER publications. In this paper we study niche markets and their importance for the dynamics of the energy system and for global warming. In particular, we analyse the nature of the substitution dynamics that may exist between fossil fuel and non-fossilfuel technologies. We do not explicitly explore the efficiency or cost-effectiveness of carbon emission (or reduction) trajectories. Instead, we simulate the carbon emission paths that arise if one levies a constant carbon tax. In particular, we look at the effect of carbon taxes at different levels, in combination with different assumptions on the elasticity of substitution between fossil and non-fossil fuels, on future carbon emissions, the share of non-fossil versus fossil fuels in

\footnotetext{
${ }^{3}$ Note that the elasticity of substitution measures the inverse of the curvature of the production isoquant. It divides the percentage change in the factor ratio (that is the change in the angle of the input vector) by the percentage change in the prices (the change in the slope of the isoquant). See, for example, Varian, 1992.
} 
energy consumption, and global temperature changes. While not incorporating - in its present version at least - any regional specification (as typically do RICE-type models), the model extends existing IAMs in two respects, and forms thereby a new contribution to the IAM literature on global warming. It combines three modelling features that previously have only been studied separately, and it adds one feature that so far has never been seriously addressed in this context. The first feature concerns the inclusion of two competing energy technologies, one of which has zero net $\mathrm{CO}_{2}$ emissions. This feature allows for emission reductions to be achieved by a transition towards a carbon-free technology, in addition to those resulting from the substitution of capital and labour for energy, e.g. through increasing energy efficiencies and the implementation of 'end-of-pipe' measures. Second, the model distinguishes old from new capital, in such a way that substitution possibilities between production factors only apply to new capital stocks. This 'putty-clay' approach allows for different short and long-term substitution elasticities and can, in particular, describe a slow diffusion process. Third, the model includes learning-bydoing through the use of learning curves. In this way, a transition towards alternative technologies leads to lower energy production costs for these alternative technologies, and thereby enhances their opportunities. This part of the model is based on the MESSAGE optimisation model developed by Messner (1997). Fourth, it includes niche markets in which new technologies can relatively easily spread - even though production costs are high - before these technologies are fully matured. Although the first three elements have been studied before mostly separately, the novelty of our analysis lies in the fact that we assemble them in one concise IAM, while in addition - and most importantly - including the notion of niche markets. The virtue of our simple but integrated model DEMETER is that we can relatively easily explore the implications of its specifications, while remaining fairly assured that other peculiar features of the model do not cause any biases in our interpretations. It is our clear intention to remain in the spheres of top-down integrated assessment modelling. This allows us to study the economy and climate interactions as a whole, with energy dynamics as an integral part of it, while still being able to differentiate between carbon and non-carbon based energy resources. We have not wanted to construct rich representations of many energy technologies, and their learning processes and sensitivities to the levying of carbon taxes, as is done already in many existing bottom-up models. We have enriched a basic top-down model by an analysis of learning-by-doing of the two available energy resources and the presence of niche markets. No regional differentiation is supposed at this stage, in order to obtain results that are at an as aggregated level as possible, like in the original DICE model.

Chapter 2 provides the complete model specification of the model DEMETER. Chapter 3 describes the input data used for the numerical analysis. Chapter 4 presents and discusses the results of our simulations. Chapter 5 concludes. 


\section{MODEL SPECIFICATION FOR DEMETER}

The model has distinct time periods of five years, each denoted by $t=1, \ldots, \infty$. The model distinguishes one representative consumer, three representative producers (also referred to as sectors), and a public agent that can set emission taxes to reduce carbon dioxide emissions. Producers are denoted by superscripts $j=C, F, N$, for the producer of the final good or Consumption good, the producer of energy based on fossil-fuel technology, and the producer of energy based on carbon-free technology. There are four goods for which an equilibrium price is determined that brings supply and demand in equilibrium: the final good with price $\lambda_{t}$ normalized to unity, $\lambda_{t}=1$, fossil fuel energy, with price $\mu_{t}^{F}$, carbon-free energy with price $\mu_{t}^{N}$, and labour with price $w_{t}$. We use $\beta_{t}^{\tau}$ as the price deflator for the final good from period $t$ to period $\tau$. So, $\beta_{t}^{\tau}=1 /\left[\left(1+r_{t}\right)\left(1+r_{t+1}\right) \ldots\left(1+r_{t-1}\right)\right]$, where $r_{t}$ is the real interest rate. By definition, $\beta_{t}^{t} \equiv 1$ and $\beta_{t}^{\tau}=1 / \beta_{\tau}^{t}$. When convenient, we also use $\beta_{t}=\beta_{t}^{t+1} \equiv 1 /\left(1+r_{t}\right)$. Figure 2.1 presents a schematic overview of the model flows. The time lag between investments and capital used as a production factor is represented through an 'L' on top of the flow arrows. ${ }^{4}$

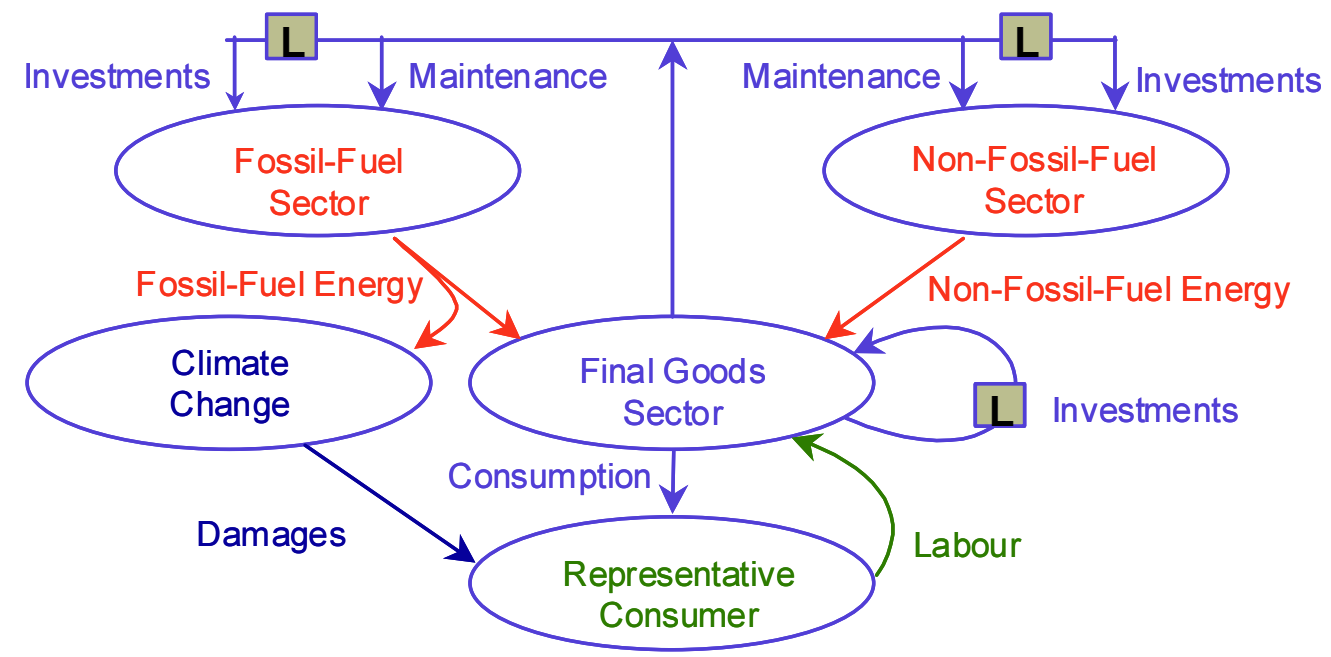

Figure 2.1 DEMETER schematic overview of flows

The final good is produced by sector $j=C$, where output is denoted by $Y^{C}$. The same good is used for consumption, investments $I$ in all three sectors and for operating and maintenance $M$ (as usually distinguished in energy models) in both energy sectors $j=F, N$ :

$$
C_{t}+I_{t}^{C}+I_{t}^{F}+I_{t}^{N}+M_{t}^{F}+M_{t}^{N}=Y_{t}^{C} .
$$

We distinguish operating \& maintenance costs, on the one hand, and investments costs, on the other hand, in the energy sector chiefly since the empirical data on learning rates often pertain to investment costs (cf. McDonald and Schrattenholzer, 2001) and we want to avoid overestimating learning rates. Fossil fuel energy is demanded by the final goods sector $j=C$ and supplied by the fossil-fuel sector $j=F$. Carbon-free energy is demanded by the final goods sector $j=C$ and supplied by the carbon-free energy sector $j=N$. Labour $L_{t}$ is demanded by the final goods sector $j=C$ and supplied inelastically by the consumers. Finally, the public agent may levy a tax $\tau_{t}$ on emissions $E m_{t}$ produced by the final good sector when using fossil-fuel energy sources.

\footnotetext{
4 The complete GAMS code is available through the internet, via the web-page of the first author: www.vu.nl/ivm/organisation/staff/reyer_gerlagh.html.
} 


\subsection{The representative consumer}

We assume there is one representative consumer who maximises welfare subject to a budget constraint:

$W=\sum_{t=1}^{\infty}(1+\rho)^{-t} L_{t} \ln \left(C_{t} / L_{t}\right)$

where $W$ is total welfare, $\rho$ is the pure time preference, and $C_{t} / L_{t}$ is consumption per capita. Welfare optimisation gives the Ramsey rule as a first-order-condition for consumption,

$\beta_{t}=\left(C_{t} / L_{t}\right) /\left((1+\rho)\left(C_{t+1} / L_{t+1}\right)\right)$.

\subsection{The final good producer}

The representative producer maximizes the net present value of the cash flows:

$\operatorname{Max} \sum_{t=1}^{\infty} \beta_{0}^{t}\left(Y_{t}^{C}-I_{t}^{C}-w_{t} L_{t}-\mu_{t}^{F} Y_{t}^{F}-\mu_{t}^{N} Y_{t}^{N}-\tau_{t} E m_{t}\right)$,

subject to the production constraints (5-12), given below. Revenues consist of output $Y_{t}^{C}$, expenditures consist of investments, $I_{t}^{C}$ (one period ahead), labour $L_{t}$ at wage $w_{t}$, fossil fuel energy $Y_{t}^{F}$ at price $\mu_{t}^{F}$, and carbon-free energy, $Y_{t}^{N}$ at price $\mu_{t}^{N}$, and the public agency levies a $\operatorname{tax} \tau_{t}$ on emissions. First order conditions are given in the appendix.

To describe production, DEMETER accounts for technology that is embodied in capital installed in previous periods. It therefore distinguishes between production that uses the vintages of previous periods, and production that uses the newest vintage for which the capital stock has been installed in the directly preceding period. The input and output variables, as well as prices, associated with the most recent vintages are denoted by tildes $(\sim)$. For every vintage, the production of the final good is based on a nested CES-function, using a capital-labour composite, $\widetilde{Z}_{t}$, and a composite measure for energy services, $\widetilde{E}_{t}$, as intermediates:

$\widetilde{Y}_{t}^{C}=\left(\left(A_{t}^{1} \widetilde{Z}_{t}\right)^{(\gamma-1) / \gamma}+\left(A_{t}^{2} \widetilde{E}_{t}\right)^{(\gamma-1) / \gamma}\right)^{\gamma /(\gamma-1)}, \quad\left(\tilde{\lambda}_{t}^{2}\right)$

where $A_{t}{ }^{1}$ and $A_{t}^{2}$ are technology coefficients, and $\gamma$ is the substitution elasticity between $\widetilde{Z}_{t}$ and $\widetilde{E}_{t}$. Notice that the Lagrange variable for the profit maximization program is given between brackets. The capital-labour composite $\widetilde{Z}_{t}$ is defined as:

$\widetilde{Z}_{t}=\left(I_{t-1}^{C}\right)^{\alpha}\left(\widetilde{L}_{t}\right)^{1-\alpha}$

which says that the capital/labour composite has fixed value share $\alpha$ for capital. Note that new capital is by definition equal to the investments of one period ahead, $\widetilde{K}_{t}^{j}=I_{t-1}^{j}$.

We model energy services $\widetilde{E}_{t}$ as consisting of a CES aggregate of energy produced by the sectors $F$ and $N$ :

$\widetilde{E}_{t}=\left(\left(\widetilde{Y}_{t}^{F}\right)^{(\sigma-1) / \sigma}+\left(\widetilde{Y}_{t}^{N}\right)^{(\sigma-1) / \sigma}\right)^{\sigma /(\sigma-1)}$,

where $\sigma$ is the elasticity of substitution between $F$ and $N$. The CES aggregation allows for a strictly positive demand for the new technology $N$, if the price of the carbon-free energy exceeds 
the price of the fossil-fuel energy $F$ even by an order of magnitude. By assuming the elasticity of substitution $\sigma$ to have a (bounded) value larger than one, $1<\sigma<\infty$, it is ensured that the (expensive) new technology has at least a small but positive value share. In this way, the CES aggregation effectively represents a niche market and enables the economic system to take advantage of a diversified energy production, e.g. because different technologies exist, each having their own markets for which they possess a relative advantage. In DEMETER, niche markets are represented on the macro level, while gradual substitution of one technology for the other technology takes place when prices change. Though one could argue that the competition between energy sources will intensify (and thus the elasticity of substitution will increase) once the market share of carbon free technologies rises as a result of a carbon tax, we assume $\sigma$ to be constant both for reasons of simplicity and for reasons of lack of empirical data. As we will argue in Chapter 3 , there is not much empirical evidence on the value of $\sigma$.

Carbon dioxide emissions, $E m_{t}$, are linked to the production of the newest vintage through an emission intensity parameter $\varepsilon_{t}^{F}$ (where $\varepsilon_{t}^{N}=0$ for the carbon-free energy technology) that describes the level of emissions per unit of fossil-fuel energy use:

$$
\tilde{E} m_{t}=\varepsilon_{t}^{F} \tilde{Y}_{t}^{F}, \quad\left(\tilde{\tau}_{t}\right)
$$

One part of production employs the new vintage, the other part employs the old capital stock that carries over from the previous period. All flows, output, use of energy, labour, and the output of emissions are differentiated between the old and the new vintages. The input/output flow in period $t$ is equal to the corresponding flow for the new vintage, plus the corresponding flow for the old capital stock of the previous period, times a depreciation factor (1- $\delta$ ).

$$
\begin{array}{ll}
Y_{t}^{C}=(1-\delta) Y_{t-1}^{C}+\widetilde{Y}_{t}^{C}, & \left(\tilde{\lambda}_{t}^{1}\right) \\
Y_{t}^{j}=(1-\delta) Y_{t-1}^{j}+\widetilde{Y}_{t}^{j}, & \left(\widetilde{\mu}_{t}^{j} ; j=F, N\right) \\
L_{t}^{j}=(1-\delta) L_{t-1}^{j}+\widetilde{L}_{t}, & \left(\widetilde{w}_{t}\right) \\
E m_{t}=(1-\delta) E m_{t-1}+\widetilde{E} m_{t} . & \left(\widetilde{\tau}_{t}\right)
\end{array}
$$

where the last equation (12) presents the relation between total emissions $E m_{t}$ and emissions of the new vintage $\widetilde{E} m_{t}$. Note that the equations should not be read as describing accumulation over time, and related thereto, the variables $Y_{t}^{C}, Y_{t}^{F}, Y_{t}^{N}, L_{t}^{C}, E m_{t}$, do not represent stock variables. Instead, the equations more-or-less describe the slow adjustment of production characteristics over time, as the capital stock slowly adjusts with new vintages in every period.

\subsection{Energy producers}

Both energy producers, the fossil fuel sector $j=F$ and the non-fossil fuel sector $j=N$ are treated symmetrically. Production of energy, $\widetilde{Y}_{t}^{j}(j=F, N)$, requires investments $I_{t-1}^{j}$ (in the previous period) and maintenance costs, $M_{t}^{j}$. Energy producers maximize the net present value of cash flows:

$\operatorname{Max} \sum_{t=1}^{\infty} \beta_{0}^{t}\left(\mu_{t}^{j} Y_{t}^{j}-I_{t}^{j}-M_{t}^{j}\right)$.

Each new vintage with output $\widetilde{Y}_{t}^{j}$ requires proportional investments one period ahead, $I_{t-1}^{j}$, and maintenance costs $\widetilde{M}_{t}^{j}$ according to:

$$
\begin{array}{rlrl}
\widetilde{Y}_{t}^{j} & =a_{t}^{j} I_{t-1}^{j}, & \left(\zeta_{j, t} ; j=F, N\right) \\
\widetilde{Y}_{t}^{j}=b_{t}^{j} \widetilde{M}_{t}^{j}, & \left(\eta_{j, t} ; j=F, N\right)
\end{array}
$$


where we maintain subscripts $t$ for the technology parameters $a_{t}^{j}$ and $b_{t}^{j}$ to describe decreasing costs of energy production (increasing levels for $a_{t}^{j}$ and $b_{t}^{j}$ ) resulting from learning-by-doing. We assume that knowledge gained is public, that is non-rival and non-exclusive. Thus firms will not internalise the positive spill-overs from their investments in their prices. Hence, production parameters $a_{t}^{j}$ and $b_{t}^{j}$ are treated as exogenous by the firms, and the individual firms are confronted with constant returns to scale. ${ }^{5}$ In a similar way as expressed in the production of consumer goods (9), energy output is distinguished by vintage (10), and the same vintage approach applies to maintenance costs, $M_{t}^{j}$ :

$$
M_{t}^{j}=(1-\delta) M_{t-1}^{j}+\tilde{M}_{t}^{j} . \quad\left(\xi_{j, t} ; j=F, N\right)
$$

Profit maximisation of (13) subject to (10),(16), (14), and (15) gives zero profits. First order conditions are listed in the Appendix.

In this formulation we have not explicitly modelled resource exhaustion. One may argue that resource depletion implies in principle increasing extraction costs that, in practice, however, is usually counter-balanced by continuous technological development that tend to reduce extraction costs over time. Looking at the expected future price trajectories for fossil fuels (e.g., Nakicenovic et al., 1998, p 111, medium scenario B), we see that the shadow-prices for all fossil fuels increase over time. We thus may underestimate the costs of supplying fossil fuels, but not too much, since expected increases in fossil fuel prices are small.

\subsection{Technological change}

The DEMETER model incorporates various insights from the bottom-up literature that stresses the importance of internalising learning-by-doing effects in climate change analyses. Energy production costs decrease as the experience increases through the installation of new energy vintages. In this version of DEMETER, the endogenous modelling of learning by doing is limited to the energy sectors; we have not included learning effects for overall productivity and energy efficiency. Thus, $A_{t}^{1}$ and $A_{t}^{2}$ as employed in (5) are exogenously determined by a benchmark (business as usual) growth path.

For the energy sector, the model describes the learning process through a scaling variable $h_{t}^{j}$ the inverse of which measures the relative productivity $a_{t}^{j}$ and $b_{t}^{j}$ relative to long-term productivity levels, $a_{\infty}^{j}$ and $b_{\infty}^{j}$.

$$
\begin{array}{ll}
h_{t}^{j} a_{t}^{j}=a_{\infty}^{j}, & (j=F, N) \\
h_{t}^{j} b_{t}^{j}=b_{\infty}^{j} . & (j=F, N)
\end{array}
$$

Stated in other terms, the variable $h_{t}^{j}$ measures the costs of one unit of output $\widetilde{Y}_{t}^{j}$ as compared to potential long-term costs. For example, $h_{t}^{j}=2$ means that one unit of energy output of sector $j$ costs twice as much investments and maintenance costs as compared to the situation in the far future when the learning effect has reached its maximum value.

To capture the process of gaining experience and a decreasing value of $h_{t}^{j}$, we introduce the variable $X_{t}$ that represents experience; it counts accumulated installed new capacity (vintage) at the beginning of period $t$ :

\footnotetext{
5 An extended version of DEMETER 1.0 also includes subsidies for new technologies, as presented in van der Zwaan et al. (2002). These can be used to internalise learning-by-doing in order to reach a dynamically efficient allocation. In this paper, however, we abstract from such subsidies.
} 
Furthermore, we use a scaling function $\mathrm{g}^{j}(X) \rightarrow[1, \infty)$ that returns the value for $h_{t}^{j}$ as dependent on cumulative experience $X_{t}^{j}$. Employing discrete time steps, the value of $h_{t}^{j}$ is given by the average value of $\mathrm{g}^{j}(X)$ over a period:

$$
h_{t}^{j}=\int_{X_{t}^{j}}^{X_{+1+1}^{j}} \mathrm{~g}^{j}(x) \mathrm{d} x /\left(X_{t+1}^{j}-X_{t}^{j}\right), \quad(j=F, N)
$$

We assume $\mathrm{g}^{\prime}() \leq$.0 , that is, production costs decrease as experience increases, and we assume $\mathrm{g}^{j}(\infty)=1$, that is, production costs converge to a strictly positive floor price (minimum amount of input associated with maximum learning effect) given by the levels of $a_{\infty}^{j}$ and $b_{\infty}^{j}$. Finally, we assume a constant learning rate $l r>0$ for technologies at the beginning of the learning curve (that is, for small values of $X$ ). This means that, initially, production costs decrease by a factor (1-lr), for every doubling of installed capacity. Such decreases have been observed empirically for a large range of different technologies (IEA/OECD, 2000).

A function $\mathrm{g}^{j}($.$) that supports all these assumptions is given by:$

$$
\mathrm{g}^{j}(X)=c^{j}\left(1-d^{j}\right) X^{-d^{j}}+1 \text {. }
$$

where we omitted subscripts $t$ and superscript $j$ for the variable $X$, and $0<d^{j}<1$ measures the speed of learning, and $c^{j}$ measures the size of the learning costs relative to the long-term production costs. ${ }^{6}$ Finally, we notice that, in a model without learning-by-doing, we would have $\mathrm{g}^{j}()=$.1 .

\subsection{Climate change}

Emissions are included in the equilibrium through equations (12) and (8). Environmental dynamics are included by linking emissions to atmospheric $\mathrm{CO}_{2}$ concentrations, Atm , and, in turn, to temperature change, Temp:

$$
\begin{aligned}
& \operatorname{Atm}_{t+1}=\left(1-\delta^{M}\right) \operatorname{Atm}_{t}+\pi\left(E m_{t}+E m_{t}\right), \\
& \operatorname{Temp}_{t+1}=\left(1-\delta^{T}\right) \operatorname{Temp}_{t}+\delta^{T} \bar{T}^{2} \ln \left(\operatorname{Atm}_{t} / A_{t m_{0}}\right),
\end{aligned}
$$

where $\delta^{M}$ is the atmospheric $\mathrm{CO}_{2}$ depreciation rate, $\pi$ is the retention rate, $\overline{E m_{t}}$ are emissions not linked to energy production, $\delta^{T}$ is the temperature adjustment rate due to the atmospheric warmth capacity, and $\bar{T}$ is the long-term equilibrium temperature change associated with a doubling of atmospheric $\mathrm{CO}_{2}$ concentrations. The climate change sub-model is based on Nordhaus (1994).

\footnotetext{
6 The learning rate $l r$ and the parameter $d$ used in (21) and (45) are approximately related by the equation $d=-\ln (1-$ $l r) / \ln 2$. For small learning rates $l r$, we make the approximation $d=l r / \ln 2$.
} 


\section{CALIBRATION AND DATA FOR NUMERICAL ANALYSIS}

For the numerical analysis presented in Chapter 4, we calibrated the model to make it comparable with other commonly used IAMs. The model describes the world economy without regional differentiation. As a reference scenario, we constructed a business-as-usual path that follows median assumptions on future population levels, gross world product, energy consumption, greenhouse gas emissions, energy prices, and investments and maintenance costs for both energy technologies. Elasticities are chosen in accordance with other models.

\subsection{Volumes}

For specifying the benchmark paths for population, gross world product (GWP), and energy use, literature is abundantly available. Population is assumed to grow from 5.89 billion in 1997 at a rate of $1.45 \%$ per year, levelling off and reaching 11.4 billion by the end of the $21^{\text {st }}$ century (compare Nakicenovic et al., 1998). GWP in 1997 is 25.1 trillion US\$1990, and the growth rate of GWP per capita is assumed to be $1.5 \%$ per year over the entire modelling horizon (World Bank, 1999). On the basis of the database developed for the IIASA-WEC study (Nakicenovic et al., 1998), final commercial energy consumption in 1997 is estimated to be $320 \mathrm{EJ}$, when measured in primary energy equivalents. ${ }^{7}$ From the same database, the share of fossil-fuel technologies in energy production (in 1997) is estimated at $96 \%$. This corresponds to 307 EJ. The remaining share of $13 \mathrm{EJ}$ is non-fossil energy. The future path for energy consumption further depends on the autonomous energy efficiency improvements (AEEI). Based on long-term evidence, we consider an AEEI of 1.0 per cent per year reasonable (Nakicenovic et al., 1998), so that the energy consumption growth decreases from 2.0 per cent per year in 2000 to 1.0 per cent per year in 2100 .

Benchmark carbon dioxide emissions further depend on the carbon intensity of the fossil-fuel technology, and on the speed of the transition towards the carbon-free technology. The latter is conditional on the energy price paths, and the substitution possibilities between the competing energy technologies, discussed further on. As for the carbon intensity, fossil fuel related carbon dioxide emissions are assumed to be $6.3 \mathrm{GtC} / \mathrm{yr}$ in 1997. As a result, the carbon emission intensity of the fossil technology is thus $0.02 \mathrm{gC} / \mathrm{MJ}$ of final energy used. $\mathrm{CO}_{2}$ emissions from industrial processes are around $0.23 \mathrm{GtC}$ in 1997, and assumed constant over time. Carbon emissions for land-use changes are estimated at $1.1 \mathrm{GtC}$ and assumed to be constant over time (see Nakicenovic et al., 2001, and Roehrl, 2000).

\subsection{Prices and production costs}

Since our model represents the two energy resources in an aggregate way, we have to make reasonable estimates for the average initial energy prices required. Because of the variability and volatility of these prices, this is not straightforward. In addition, the literature provides insufficient evidence on the elasticity of substitution between the two energy technologies, $\sigma$ in (7), to justify a certain choice. Therefore, and because of the expected importance of the parameter for the results, we carried out a sensitivity analysis on this parameter. As our model serves mainly for analysing the dynamics of the energy system, approximate estimates suffice.

\footnotetext{
7 We want to make to remarks on this. First, the number excludes non-commercial biomass use, as well as traditional carbon-free sources such as nuclear and hydropower. Second, without conversion to primary energy equivalents, final energy consumption is estimated to be $265 \mathrm{EJ}$ per year.
} 
Prices for final energy derived from natural gas technologies vary in a range from 2 to 3 $\$(1990) / G J .^{8}$ Since coal, oil and natural gas are, grosso modo, competitive, a good reference price in our calculations for the average fossil-fuel energy resource is $2.5 \$ / G J$, in the modelstart-off year 1997. A large spread exists in production costs for energy from wind, solar and biomass options. Prices for commercial final electricity from wind turbines varied in 1995 between 5 and $20 \$(1990) / G J$, in the highest-cost and lowest-cost production cases, respectively. ${ }^{9}$ Whereas electricity production costs for photovoltaics are still significantly higher than that for wind energy, costs of electricity derived from biomass are comparable to that of wind energy. ${ }^{10}$ The average price of final energy by the non-fossil technology is taken to be $7.0 \$ / G J$, in the year 1997. This value is merely taken as an example from the range of current feasible wind electricity prices; it represents a realistic figure of the current cost of some non-carbon energy alternative, generically speaking.

While it is difficult to come up with aggregate energy prices for both technologies, they are of utmost importance for the various scenarios, since the relative prices in conjunction with the relative shares imply an assumed elasticity of substitution between the two technologies. From the CES aggregation of both fossil and carbon-free energy types, in relation (7), we derive:

$$
\left(Y_{t}^{F} / Y_{t}^{N}\right) \approx\left(p_{t}^{N} / p_{t}^{F}\right)^{\sigma},
$$

where the approximation sign ' $\approx$ ' indicates that current prices do not completely determine current shares due to the vintages. Prices in future periods also affect the optimal choice of the technology mix for current new vintages, and, in turn, present prices have affected the optimal technology mix of past vintages. Since, in 1997, the estimated ratio between the volumes for fossil and non-fossil technologies has been 24:1, an elasticity of substitution of $\sigma=3$ is approximately consistent with a price ratio of $1: 2.8$, reflecting the price ratio $(2.5 \$ / G J$ and $7.0 \$ / G J)$ chosen above. The assumed substitution possibilities of the carbon-free technology for the fossil-fuel technology, reflected in the value of $\sigma$, is of crucial importance for the speed of market penetration. A high elasticity implies that market shares react strongly to even a modest decrease in future production costs due to gained experience. A low elasticity, on the other hand, implies a relatively slow penetration rate. Since there is not much empirical evidence on the value of $\sigma$, we carried out a sensitivity analysis and present most results for three values: $\sigma=2,3,4$.

We also make explicit assumptions on the distribution of production costs over investments and maintenance and operation (M\&O) costs, (14) and (15), as well as on the floor of the energy production costs. For fossil fuels, the assumed distribution of costs over investments and M\&O is 20:80, where for convenience the fuel part of the costs is integrated in the M\&O costs. For non-fossil technologies, the assumed ratio is 80:20 (Schönhart, 1999). In combination with the assumed energy prices, one sees that investment costs for non-fossil energy are assumed to be currently about 10 times those for fossil energy. For the long term, the same potentials for cost reductions are assumed to exist for new gas and coal technologies as for non-fossil fuel energy sources. The long-term floor price for both energy sources is fixed at $1.25 \$ / G J$. As such, noncarbon energy has the potential to become fully competitive with carbon energy, though investment costs will remain 4 times the investment costs for fossil energy.

\footnotetext{
8 See, for example, IEA/OECD, Key World Energy Statistics, Paris, 1999, p.41.

9 See, for example, IEA/OECD, Experience Curves for Energy Technology Policy, Paris, 2000, p.54. In fig.3.3 in this publication, one sees that in 1995 (in the EU) wind energy production costs varied from about 0.02 to $0.08 \mathrm{ECU}(1990) / \mathrm{kWh}$. Assuming an approximate equivalence between the ECU and \$, as well as the conversion factor of 3.6 in going from GWh to TJ (that is, 0.0036 from $\mathrm{kWh}$ to GJ), one obtains the range quoted here.

${ }^{10} \mathrm{See}$, for example, IEA/OECD, op. cit., p.21.
} 
The learning rate for non-fossil energy resources is assumed to be $20 \%$ per doubling of installed capacity, in line with the empirical evidence on this variable for solar power and wind suggesting that the rate ranges from 8 to $35 \%$, with an average of around 20\% (McDonald and Schrattenholzer, 2001). On the other hand, the fossil energy technology is assumed to have used most of its learning potentials already. We emphasise that the learning rate specified for the energy technologies is in excess of the overall increase in productivity for the economy as a whole. That is, productivity growth in the fossil-fuel sector is not absent, but is assumed to reach the same level as productivity growth for the aggregate economy. On the other hand, the productivity growth for non-fossil energy technologies is assumed to exceed the productivity growth for the economy as a whole by $20 \%$ for every doubling of the installed capacity. The cumulative installed capacity up to the year 2000 is calculated to be about $1250 \mathrm{EJ} / \mathrm{yr}$ and 33 $\mathrm{EJ} / \mathrm{yr}$ for the fossil energy option and the non-fossil energy alternative, respectively. ${ }^{11}$ Under business as usual, the cumulative installed capacity for the carbon-free energy technology is doubled by 2020 . Consequently, production costs have decreased by $20 \%$, and for $\sigma=3$ the market share will have increased by approximately $60 \%$, or 2.5 per cent points, from $4 \%$ to $6.5 \%$. For other values of $\sigma$, different $\mathrm{BaU}$ penetration rates appear as shown in Figure 4.1.

Finally, the carbon tax imposed in the scenarios will decrease energy demand, the amount of which depends on the elasticity of energy consumption. We assumed a long-term elasticity of energy consumption to energy prices of 0.4 (Manne, 1999). Due to the vintage structure of the model, it takes time to adjust the capital stock to price changes, so that short-term elasticities are much lower.

\footnotetext{
${ }^{11}$ Note that the unit of measurement for the energy production capacity corresponds to the flow of energy that is produced by the installed capacity. For example, for electricity production, TW is a common unit of measurement, equivalent to $0.032 \mathrm{EJ} / \mathrm{yr}$.
} 


\section{SIMULATION RESULTS}

In this Chapter we will analyse the effects of different levels of a carbon tax and of different values of the elasticity of substitution. First, we will examine the impact of different carbon taxes maintaining the central value for the substitution elasticity, $\sigma=3$. Subsequently, we examine the share of carbon free fuels as well as the development of global carbon emission under a $50 \$ / \mathrm{tC}$ tax with different elasticities of substitution, $\sigma=2,3,4$. A tax of $\$ 50 / \mathrm{tC}$ is roughly equivalent to a $50 \%$ increase in the price of fossil energy. Finally, we illustrate the resulting global temperature changes.

Figure 4.1 shows the effect, in our model, that different carbon tax levels have on carbon emission paths. In the $\mathrm{BaU}$ scenario, emissions increase steadily to a value of about $15 \mathrm{GtC} / \mathrm{yr}$ in 2100. This result is in line with the modest growth B2-scenarios of the IPCC report (Nakicenovic et al. 2001), which suggest carbon emissions of 11 to $22 \mathrm{GtC}$ from the different models.

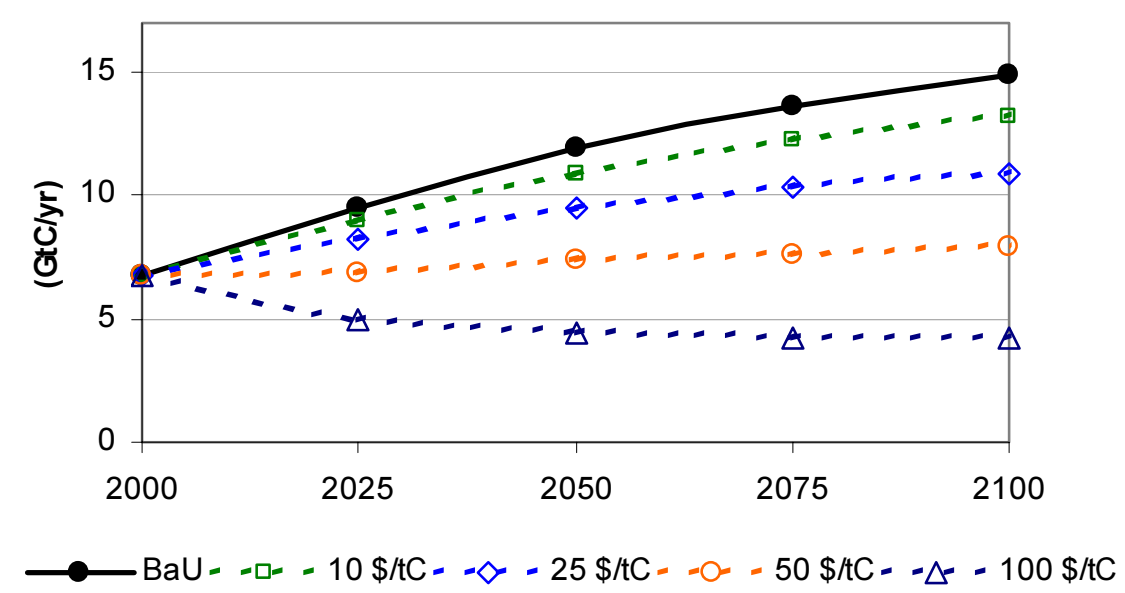

Figure 4.1 Carbon emissions for BaU and different constant carbon tax levels, $\sigma=3$

The other four scenarios, implying a (constant-over-time) carbon tax of $10 \$ / \mathrm{tC}, 25 \$ / \mathrm{tC}, 50 \$ / \mathrm{tC}$, and $100 \$ / \mathrm{tC}$, respectively, realise each an additional reduction of about $3 \mathrm{GtC} / \mathrm{yr}$ around the year 2100. Due to the vintage approach of the model, a reduction in emissions takes time. In the long-term, substitution possibilities exceed the short-term possibilities. The model avoids an unrealistic immediate cut in 2000, which we find in many other macro-economic models. With a tax of $50 \$ / \mathrm{tC}$, an almost constant emission level can be achieved throughout the $21^{\text {st }}$ century. Such a tax suffices to keep the atmospheric carbon dioxide concentration below a doubling with respect to the pre-industrialisation value of 280 parts-per-million by volume (ppmv), during the $21^{\text {st }}$ century. Given the result of earlier IAMs, the taxes we need for emission stabilisation are very low. E.g. Nordhaus (1994) argues that his DICE model requires initially tax levels that are not higher than some $20 \$ / \mathrm{tC}$. In the long run, however, taxes are needed that run into hundreds of dollars per ton carbon, that is, if the aim is to stabilise carbon emissions. Results from the MESSAGE-MACRO model for the IPCC-B2 scenario suggest that the carbon tax would need to increase from $140 \$ / \mathrm{tC}$ in 2020 to around $500 \$ / \mathrm{tC}$ in 2100 to bring carbon emissions back to their 1990 levels in order to stabilize concentrations at 550 ppmv in the year 2100 (Riahi and Roehrl, 2000).

The reason for the low levels of carbon taxes in our model is that the main mechanism for emission reduction consists of a transition from fossil fuels towards the carbon-free technology. This transition is not very costly in DEMETER, in comparison to other models. The explanation of 
this is two-fold. First, the presence of niche markets which is modelled through the CES aggregation of fossil-fuel and non-fossil-fuel energy (7) implies that, though the price of the nonfossil energy technology is higher than that of the conventional fossil-fuel energy, there are many users of the fossil fuel based energy technology for whom a shift towards the more expensive non-fossil energy alternative implies only a limited increase in costs. ${ }^{12}$ It should be noted that this does not imply that a transition requires no additional investments. Extra investments in the carbon free technologies are needed, and the level thereof is endogenously determined in the model. Second, the presence of the learning-by-doing effect implies that, in the long term, production costs for the new technology decrease substantially. Thereby, it becomes easier to invest in this new technology, and the market for the carbon-free alternative expands. This phenomenon contributes to the reduction of the costs involved in the transition from the carbon to the carbon-free energy alternative. Finally, the relatively low tax level is also related to the fact that we assume relatively modest GDP growth rates as well as autonomous decarbonisation within the fossil-fuel technologies. Scenarios with high GDP growth rates lead to significantly higher unabated baseline emissions (Nakicenovic et al., 1998, 2001), therefore requiring higher marginal taxes to reach the same absolute emission constraints.

The modelling of the presence of niche markets makes the substitution parameter $\sigma$ central to our analysis of endogenous technological change, and renders this parameter of main importance to a sensitivity analysis. Though we have carried out an extensive sensitivity analysis to all parameters, we restrict ourselves in this paper to reporting only on a sensitivity analysis with respect to $\sigma .{ }^{13}$ We compare two scenarios: BAU, without any carbon tax, on the one hand, and the imposition of a constant-over-time carbon tax of $50 \$ / \mathrm{tC}$, on the other hand. In both cases, we vary $\sigma$ over three values - 2, 3, and 4 - representing different levels of substitutability between the fossil and non-fossil energy alternatives. We expect that a higher value of the substitution parameter, $\sigma=4$, will further speed up the transition towards the new carbon-free technology. The reason for such an expected accelerated transition of the energy system is that the same reduction in production costs for the new technology now has a stronger effect on its demand, when the substitution opportunities are high for this technology. Inversely, a lower value for $\sigma$ is expected to result in a slower transition path. Figure 4.2 confirms these expectations. We have drawn the shares of the new technology for the two scenarios $\mathrm{BaU}$ and the $50 \$ / \mathrm{tC}$ carbon tax, as well as its dependence on different values for $\sigma$.

\footnotetext{
${ }^{12}$ Recall that the existence of niche markets implies that a group exists of consumers to whom it proves profitable, at actual prices, to use the more expensive non-fossil energy technology.

${ }^{13}$ The elaborate sensitivity analysis we have carried out shows that, together with the elasticity of substitution, the learning rate and the autonomous energy efficiency improvement are of major importance for the simulated emission paths. Changes in the elasticity of energy demand for energy prices, the capital depreciation rate, the discount rate, and the share of capital in overall production turn out to have only minor effects. For the first few decades, the results are also relatively independent of the floor in the production costs for the two technologies.
} 


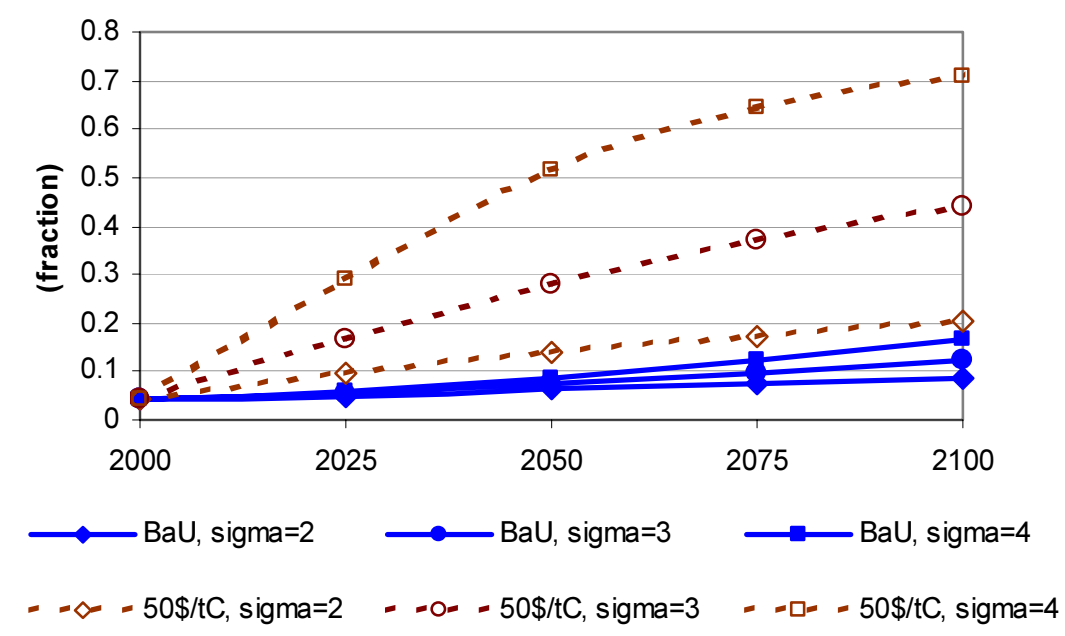

Figure 4.2 Non-carbon energy share for BaU and 50\$/tC carbon tax and different $\sigma$

The two circled lines in Figure 4.2 represent the scenarios for which $\sigma=3$. The spread in the triple of dashed lines and solid lines demonstrates the sensitivity of our results to the assumed substitutability level $\sigma$. In the BaU scenario, with a substitutability $\sigma=3$, we see that the non-carbon energy share does not increase to above $15 \%$ of total energy consumption by 2100 . This explains the increasing carbon emissions in this scenario, throughout the entire $21^{\text {st }}$ century. However with $\sigma=4$, the non-carbon share attains a level of $20 \%$ of total energy consumption, by the end of the century.

If the assumption of the existence of considerable niche markets is complemented by a tax on carbon emissions, the picture changes drastically. A tax of $50 \$ / \mathrm{tC}$, in addition to the assumption of $\sigma=3$, is sufficient for letting the non-carbon share reach about $45 \%$ of total energy consumption by the year 2100. Apparently, this share corresponds to a stabilisation of emissions at current emission levels, but not of concentrations. To stabilise carbon concentrations (at 470 ppmv), a constant tax equal to $50 \$ / \mathrm{tC}$ suffices only if the substitutability level is as high as $\sigma=4$. With this combination of taxes and niche markets, a non-carbon energy share of about $90 \%$ is attained by 2100 .

Grübler et al. (1999a, 1999b) and Knapp (1999) express technological diffusion as the time that evolves between the moment a technology has a market share of $10 \%$ and the moment this share achieves a value of $90 \%$. In Gruebler et al. a list is provided of such diffusion times, regarding a large variety of technologies (both in the energy domain, as technologies generically speaking) that have emerged over the past two centuries. The diffusion times reported are typically in the order of 50-100 years. Figure 4.2 shows that in the tax plus high substitutability case, the energy share can increase from less than $5 \%$ to $70 \%$ in one century. This result is well compatible with the empirical analysis of Gruebler et al., and we conclude that the transition of the energy system is empirically achievable. One could argue that, whereas Gruebler et al. specify diffusion times for rather specific technologies, in DEMETER we employ only a very aggregated form of a non-carbon energy alternative. We would expect a slightly longer diffusion time period for an aggregate form of energy since the aggregate S-curve consists of several subsequent S-curves for separate technologies. This can explain why we need supporting taxes to effectuate the transition in one century. On the other hand, we note that Chakravorty et al. (1997) advocate a somewhat more optimistic view of the opportunities available to radically transform the energy system.

The results shown in Figure 4.2 carry over straightforwardly to the carbon emission paths (see Figure 3). In the $\mathrm{BaU}$ scenario, assuming a substitutability as high as $\sigma=4$, annual emissions reach a level of around $13 \mathrm{GtC} / \mathrm{yr}$ in 2100 . In the case of any lower value of $\sigma$, emissions con- 
tinue increasing throughout the entire $21^{\text {st }}$ century. In the $50 \$ / \mathrm{tC}$ scenario, $\sigma=3$ suffices to reach an approximate stable level of annual carbon emissions. With any lower value for $\sigma$, we encounter again increasing emissions throughout the $21^{\text {st }}$ century. Of our six scenarios, only when the tax of $50 \$ / \mathrm{tC}$ is combined with a $\sigma=4$ substitutability level we can obtain a significant decrease in annual carbon emissions. Long-term emissions are then stabilised at a level as low as $5 \mathrm{GtC} / \mathrm{yr}$.

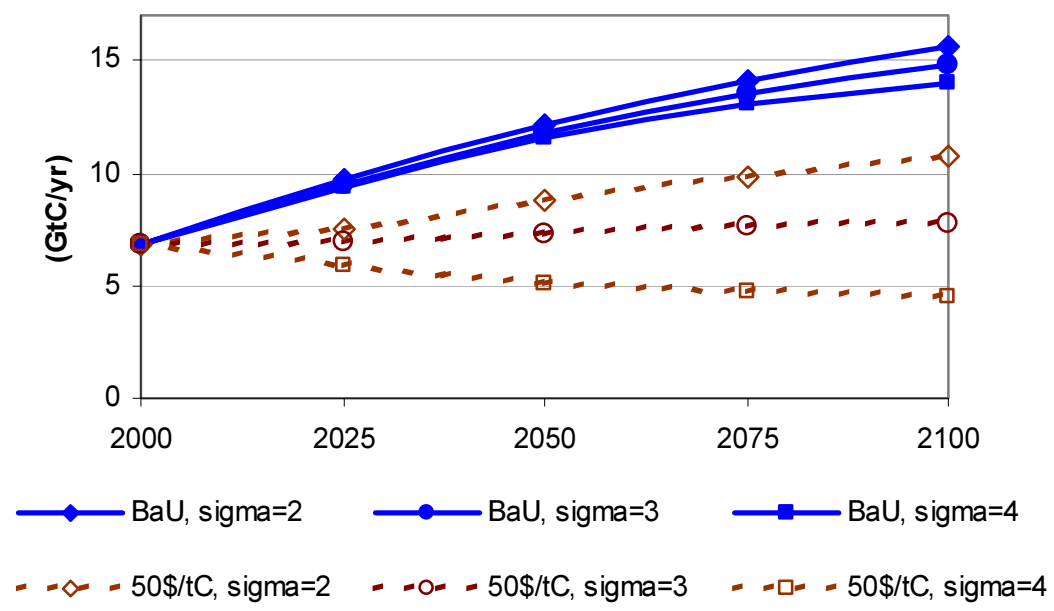

Figure 4.3 Carbon emissions for BaU and 50\$/tC carbon tax and different $\sigma$

For policy analysis, the more relevant question to answer is whether mankind is able to stabilise atmospheric carbon dioxide concentrations, or global average warming, rather than annual carbon emissions. Future carbon concentrations determine the temperature increase the atmosphere and earth's surface will undergo. Figure 4.4 shows the evolution of the average global surface (atmospheric) temperature. Our calculations show that a constant carbon tax of $50 \$ / \mathrm{tC}$ and a substitutability assumed to be $\sigma=4$ might stabilize carbon concentrations around $470 \mathrm{ppmv}$ during the entire $21^{\text {st }}$ century, and beyond. This would typically be consistent with attempts to let the global average surface temperature not increase by more than $2{ }^{\circ} \mathrm{C}$. While the central $50 \$ / \mathrm{tC}$ tax scenario constrains the temperature increase below $2{ }^{\circ} \mathrm{C}$ during the $21^{\text {st }}$ century, the temperature is clearly increasing by 2100 , so that, in the $22^{\text {nd }}$ century, the temperature increase will exceed $2{ }^{0}$ Celsius.

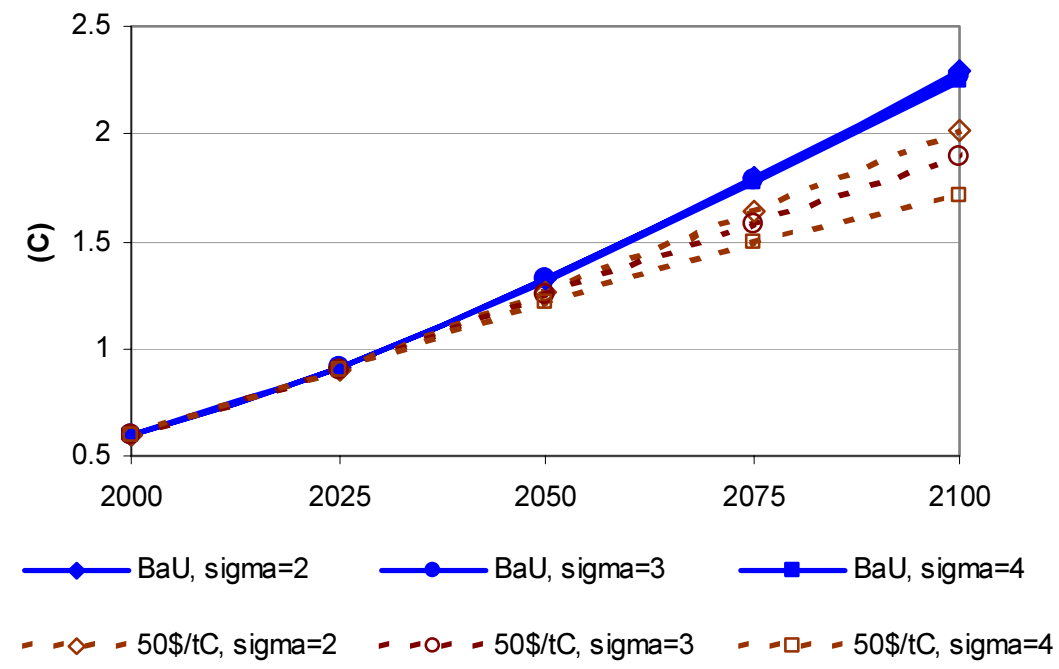

Figure 4.4 Global average atmospheric temperature change, relative to pre-industrial levels, for BaU and $50 \$ / t C$ carbon tax and different $\sigma$ 


\section{CONCLUSIONS}

If in the future substantial emission reductions are aimed at, a radical transition from fossil fuels towards carbon-free energy technologies will be a necessary element of environmental policy. Such a transition can only be successful if production costs decrease significantly, allowing the new technologies to become competitive with the existing carbon-rich technologies. The purpose of this paper is to fill a gap in the current IAM literature, by employing a CGE model (DEMETER), which includes technological change as an endogenous process (based on learning-by-doing), as well as niche markets for new carbon-free energy technologies. With this model, we have analysed the effects of different carbon taxes on emission levels. Numerical simulations with DEMETER suggest that including both niche markets and endogenous technological progress implies that carbon taxes can be substantially lower to meet given carbon constraints - in the form of emission stabilisation targets or atmospheric concentration targets - than those that have been suggested so far in the literature. With realistic assumptions on GDP growth, population growth, autonomous energy efficiency improvement and decarbonisation, and with an elasticity of substitution between fossil and non-fossil energy equal to 3 , a tax level of $50 \$ / \mathrm{tC}$ could achieve an almost constant emission level throughout the $21^{\text {st }}$ century.

We have investigated the robustness of our results under changes in our assumptions on the existence of niche markets. It appears that niche markets can alter considerably the outcomes of policy analyses regarding the taxes required for combating global warming. Indeed, conventional IAMs generally come up with high levels of carbon taxes to mitigate climate change, but usually neglect the impact niche markets can have on the energy system. Our results crucially depend on the elasticity of substitution between the fossil-fuel technology and the carbon-free technology, and on the fact that the existence of niche markets 'automatically' leads to substantially increasing market shares. Overall, our results make clear that a higher elasticity of substitution drives up the emission reductions that can be achieved for a given carbon tax. Since limited empirical evidence is available that could substantiate the choice of the proper value that ought to be taken for the elasticity of substitution, there is no clear answer to the question what tax level is necessary to attain for a certain emission target policy. Given the sensitivity of the results to this elasticity, we advocate that empirical research is undertaken to determine the values of energy substitutability levels in niche markets. More knowledge on these values would give means to evaluate the DEMETER results regarding the diffusion of non-fossil energy technologies, and the climate change merits of such a technology diffusion.

We are aware of some of the limitations of our calculations. First, simulated paths of a number of central variables highly depend on the choice for the various parameters, for which we have only limited empirical data. We have often needed to estimate their value. This especially holds for the elasticities of substitution that drive the results. No long time series (100 years) are available to support assumptions on constant or changing elasticities over such a time horizon. Second, the model includes endogenous technical change in a stylised way as depending on cumulative experience. R\&D expenditures, be it public or private, are not included as factor. With other references in the literature (such as Buonnano et al., 2001, and Buonnano et al., 2003) as starting point, we still plan to do so. We also do not model technical progress in relation to resource depletion. Bearing in mind the above observations we still think that the main results stand, independently of this parameter choice. This is especially true for two of our results. First, the further development of new energy technologies that replace conventional fossil-fuel based energy technologies is of crucial importance when aiming at substantial emission reductions. Second, the level of carbon taxes required to implement a significant transition towards new technologies may not be as high as most models suggest, notably those that do not distinguish various technologies, or those that abstract from niche markets in which a particular technology possesses a relative advantage. 


\section{REFERENCES}

Boyd, R. and N.D. Uri (1991): An assessment of the impacts of energy taxes, Resources and Energy 13: 349-379.

Beltratti, A. (1997): Growth with Natural and Environmental Resources, in: C. Carraro and D. Siniscalco, eds., New Directions in the Economic Theory of the Environment, Cambridge University Press, Cambridge.

Bovenberg A.L. and S.A. Smulders (1995): Environmental quality and pollution-augmenting technological change in a two-sector endogenous growth model, Journal of Public Economics 57: 369-391.

Bovenberg, A.L., and S.A. Smulders (1996): Transitional Impacts of Environmental Policy in an Endogenous Growth Model, International Economic Review 37: 861-893.

Buonanno, P., C. Carraro, E. Castelnuovo and M. Galeotti (2001): Emission trading restrictions with endogenous technological change, International Environmental Agreements; Law, Politics, Economics.

Buonanno, P., C. Carraro, and M. Galeotti (2003): Endogenous induced technical change and the costs of Kyoto, Resource and Energy Economics 25:11-34.

Carraro C. and M.Galeotti (1997): Economic growth, international competitiveness and environmental protection: $R \& D$ innovation strategies with the WARM model, Energy Economics 19: 2-28.

Chakravorty U., J. Roumasset, and K. Tse (1997): Endogenous substitution among energy resources and global warming,, Journal of Political Economy 105: 1201-1234.

Dasgupta, P. and G. Heal (1979). Economic Theory and Exhaustible Resources. Cambridge: Cambridge University Press.

Den Butter F.A.G. and M.W.Hofkes (1995): Sustainable development with extractive and non-extractive use of the environment in production, Environmental and Resource Economics 6: 341-358.

Gerlagh, R., and B.C.C. van der Zwaan (2003): Gross World Product and Consumption in a Global Warming Model with Endogenous Technological Change, Resource and Energy Economics 25: 35-57.

Gradus R.H.J.M. and S.A.Smulders (1993): The trade-off between environmental care and long-term growth; pollution in three prototype growth models, ournal of Economics 58: $25-51$.

Goulder L.H. and K. Mathai (2000): Optimal $\mathrm{CO}_{2}$ abatement in the presence of induced technological change, Journal of Environmental Economics and Management 39: 138.

Goulder L.H. and S.H. Schneider (1999): Induced technological change and the attractiveness of $\mathrm{CO}_{2}$ abatement policies, Resource and Energy Economics 21: 211253.

Grübler A. and S. Messner (1998): Technological change and the timing of mitigation measures, Energy Economics 20: 495-512.

Grübler A., N. Nakicenovic, and D.G. Victor (1999a): Dynamics of energy technology and global change, Energy Policy 27: 247-280. 
Grübler A., N. Nakicenovic, and D.G. Victor (1999b): Modeling technological change, implications for the global environment, Annual Review of Energy and the Environment 24: 545-569.

Hofkes M.W. (1996): Modelling Sustainable Development: an economy-ecology integrated model, Economic Modelling, 13: 333-353.

IEA/OECD (1999): Key World Energy Statistics. Paris: IEA/OECD.

IEA/OECD (2000): Experience Curves for Energy Technology Policy. Paris: IEA/OECD.

Jorgenson, D.W., and P.J. Wilcoxen (1993a): Reducing U.S. carbon dioxide emissions, an assessment of different instruments, Journal of Policy Modeling 15: 491-520.

Jorgenson, D.W., and P.J. Wilcoxen (1993b): Reducing U.S. carbon dioxide emissions: an econometric general equilibrium assessment, Resource and Energy Economics 15: $7-25$.

Knapp, K. (1999): Exploring energy technology substitution for reducing atmospheric carbon emissions, The Energy Journal 20: 121-143.

Manne, A. (1999): Internet: http://www.stanford.edu/group/MERGE/REF.GMS. Listing of the MERGE-3 code.

Manne, A.S. and R. Richels (1992): Buying greenhouse insurance. Cambridge, MA: MIT Press.

McDonald, A. and L. Schrattenholzer (2001): Learning rates for energy technologies, Energy Policy 29: 255-261.

Messner, S. (1995): Endogenized technological learning in an energy systems model. Mimeo WP-95-114, Laxenburg Austria: IIASA.

Messner, S. (1997): Endogenized technological learning in an energy systems model, Journal of Evolutionary Economics 7: 291-313.

Nakicenovic, N. A. Grübler and A. McDonald, eds. (1998). Global energy perspectives. IIASA-WEC. Cambridge, UK: Cambridge University Press.

Nakicenovic, N. et al., eds. (2001): Special Report on Emission Scenarios. Published for the Intergovernmental Panel on Climate Change (IPCC). Cambridge, UK: Cambridge University Press.

Newell R.G., A.B. Jaffe and R.N. Stavins (1999): The induced innovation hypothesis and energy-saving technological change, Quarterly Journal of Economics 114: 941-975.

Nordhaus W.D. (1994): Managing the global commons. Cambridge, MA: MIT Press.

Nordhaus, W.D. (2002): Modeling induced innovation in climate change policy. Ch. 9 in Modeling induced innovation in climate change policy, A. Grubler, N. Nakićenović, and W.D. Nordhaus (eds), Resources for the Future Press, Washington D.C.

Paper for workshop Induced Technological Change and the Environment, June 21-22, 1999, IIASA. Laxenburg, Austria.

Odell P.R. (1999): Dynamics of energy technologies and global change, Energy Policy 27: 737-742.

Peck S.C. and T.J. Teisberg (1992): CETA: a model for carbon emissions trajectory assessment, Energy Journal 13: 55-77.

Riahi, K. and A. Roehrl (2000): Greenhouse gas emissions in a dynamics-as-usual scenario of economic and energy development, Technological Forecasting and Social Change 63: 175-205. 
Schönhart, W. (1999): Assessment of future energy technology characteristics. Diplomarbeit, Austria : Technical University Graz.

Smulders S.A. (1999): Endogenous growth theory and the environment, Handbook of environmental and resource economics, Ch. 42, edited by J.C.J.M.v.d.Bergh. Edward Elgar.

Stephan G., G. Müller-Fürstenberger, and P. Previdoli (1997): Overlapping generations or infinitely-lived agents: intergenerational altruism and the economics of global warming, Environmental and Resource Economics 10: 27-40.

Varian, H. (1992): Microeconomic Analysis, $3^{\text {rd }}$ edition, Norton \& Company, New York, 1992.

Verdier, T. (1995): Environmental Pollution and Endogenous Growth, in C. Carraro and J. Filar, eds., Control and Game-Theoretic Models of the Environment, Birckauser, Boston.

World Bank (1999): 1999 World development indicators, Washington, DC: World Bank.

Zwaan, B.C.C van der., R. Gerlagh, G. Klaassen, and L. Schrattenholzer (2002):

Endogenous technological change in climate change modelling, Energy Economics 24:1-19. 


\section{APPENDIX 1 FIRST ORDER CONDITIONS FOR PROFIT MAXIMIZATION}

\section{The final good producer}

Maximizing net profits (4), subject to the constraints (5)-(12) yields the following first order conditions for $Y_{t}^{C}, Y_{t}^{j}(\mathrm{j}=\mathrm{F}, \mathrm{N}), \mathrm{L}_{\mathrm{t}}, \mathrm{Em}_{\mathrm{t}}, \widetilde{Z}_{t}, I_{t}^{C}, \widetilde{L}_{t}, \widetilde{E}_{t}, \widetilde{Y}_{t}^{j}$ :

$$
\begin{array}{ll}
\tilde{\lambda}_{t}=(1-\delta) \beta_{t} \tilde{\lambda}_{t+1}+1 & \left(Y_{t}^{C}\right) \\
\widetilde{\mu}_{t}^{j}=(1-\delta) \beta_{t} \widetilde{\mu}_{t+1}^{j}+\mu_{t}^{j} & \left(Y_{t}^{j}, j=F, N\right) \\
\widetilde{w}_{t}^{j}=(1-\delta) \beta_{t} \widetilde{w}_{t+1}^{j}+w_{t}^{j} & \left(L_{t}\right) \\
\tau_{t}=\widetilde{\tau}_{t}-(1-\delta) \beta_{t} \widetilde{\tau}_{t+1} & \left(E m_{t}\right) \\
\widetilde{\theta}_{t}=\widetilde{\lambda}_{t}^{2}\left(A_{t}^{1}\right)^{(\gamma-1) / \gamma}\left(\widetilde{Z}_{t} / \widetilde{Y}_{t}^{C}\right)^{-1 / \gamma} & \left(\widetilde{Z}_{t}\right) \\
1=\beta_{t} \widetilde{\theta}_{t+1} \alpha \widetilde{Z}_{t+1} / I_{t}^{C} & \left(I_{t}^{C}\right) \\
\widetilde{w}_{t} \widetilde{L}_{t}=(1-\alpha) \widetilde{\theta}_{t} \widetilde{Z}_{t+1} & \left(\widetilde{L}_{t}\right) \\
\widetilde{\chi}_{t}=\widetilde{\lambda}_{t}^{2}\left(A_{t}^{2}\right)^{(\gamma-1) / \gamma}\left(\widetilde{E}_{t} / \widetilde{Y}_{t}^{C}\right)^{-1 / \gamma} & \left(\widetilde{E}_{t}\right) \\
\widetilde{\mu}_{t}^{j}+\varepsilon_{t}^{j} \widetilde{\tau}_{t}=\widetilde{\chi}_{t}\left(\widetilde{Y}_{t}^{j} / \widetilde{E}_{t}\right)^{-1 / \sigma} & \left(\widetilde{Y}_{t}^{j} ; j=F\right) \\
\widetilde{\mu}_{t}^{j}=\widetilde{\chi}_{t}\left(\widetilde{Y}_{t}^{j} / \widetilde{E}_{t}\right)^{-1 / \sigma} & \left(\widetilde{Y}_{t}^{j} ; j=N\right)
\end{array}
$$

where the variables associated with the first order conditions are given between brackets, $\tilde{\lambda}_{t}$ is the shadow price for $\widetilde{Y}_{t}^{C}$, that is the Lagrange variable for (9), which is the same as the Lagrange variable for (5), $\widetilde{\mu}_{t}^{j}$ is the shadow price for $\widetilde{Y}_{t}^{j}$, and the Lagrange variable for (10), $\widetilde{w}_{t}$ is the shadow price for $\widetilde{L}_{t}$, and the Lagrange variable for (11), $\widetilde{\tau}_{t}$ is the shadow price for $\widetilde{E} m_{t}$ and the Lagrange variable for (12), which has the same value as the Lagrange variable for (8), $\widetilde{\theta}_{t}$ is the shadow price for the labour/capital composite $\widetilde{Z}_{t}$ and the Lagrange variable for (6), $\widetilde{\chi}_{t}$ is the shadow price for the energy composite $\widetilde{E}_{t}$ and the Lagrange variable for (7).

\section{Energy producers}

Using an auxiliary variable $Q_{t}^{j}$ we can rewrite (14), (15), (17) and (18) as:

$$
\begin{array}{ll}
h_{t}^{j} \widetilde{Y}_{t}^{j}=Q_{t}^{j} & \left(\varphi_{j, t} ; j=F, N\right) \\
Q_{t}^{j}=a^{j} I_{t-1}^{j} & \left(\zeta_{j, t} ; j=F, N\right) \\
Q_{t}^{j}=b^{j} \tilde{M}_{t}^{j} & \left(\eta_{j, t} ; j=F, N\right)
\end{array}
$$

The energy producers maximize net profits (13) subject to (10), (16), (35), (36), and (37). Calculating the first order conditions for $Y_{t}^{j}, \widetilde{Y}_{t}^{j}, Q_{t}^{j}, \widetilde{M}_{t}^{j}, I_{t-1}^{j}$, and $M_{t}^{j}$, we find (26) and

$$
\begin{array}{rlrl}
\widetilde{\mu}_{t}^{j} & =h_{t}^{j} \varphi_{t}^{j} & & \left(\widetilde{Y}_{t}^{j}, j=F, N\right) \\
\varphi_{t}^{j} & =\zeta_{t}^{j}+\eta_{t}^{j} & & \left(Q_{t}^{j}, j=F, N\right) \\
\widetilde{\xi}_{t}^{j}=b^{j} \eta_{t}^{j} & & \left(\widetilde{M}_{t}^{j}, j=F, N\right) \\
1=a^{j} \beta_{t} \zeta_{t+1}^{j} & & \left(I_{t-1}^{j}, j=F, N\right) \\
\widetilde{\xi}_{t}^{j}=(1-\delta) \beta_{t} \widetilde{\xi}_{t+1}^{j}+1 & & \left(M_{t}^{j}, j=F, N\right)
\end{array}
$$


respectively, where $\widetilde{\mu}_{t}^{j}$ is the shadow price for $\widetilde{Y}_{t}^{j}$, and the Lagrange variable for (10), $\varphi_{t}^{j}$ is the shadow price of $Q_{t}^{j}$ and the Lagrange variable of (35), $\zeta_{t}^{j}$ and $\eta_{t}^{j}$ are the Lagrange variables of (36), and (37), and $\widetilde{\xi}_{t}^{j}$ is the shadow price of $\widetilde{M}_{t}^{j}$ and the Lagrange variable of (16). 


\section{APPENDIX 2 FULL SPECIFICATION OF EQUILIBRIUM EQUATIONS AND VARIABLES}

We can now characterise the equilibrium by its variables, its equations and its first order conditions. The endogenous variables are $C_{t}, Y_{\sim^{C}}^{C}, \widetilde{Y}_{t}^{C}, Y_{t}^{j}(j=F, N), \widetilde{Y}_{t}^{j}(j=F, N), L_{t}, \widetilde{L}_{t}, E m_{t}, \widetilde{E} m_{t}$, $\widetilde{Z}_{t}, I_{t}^{C}, I_{t-1}^{j}(j=F, N), \widetilde{E}_{t}, Q_{t}^{j}, M_{t}^{j}, \widetilde{M}_{t}^{j}$, and $h_{t}^{j}$ for endogenous technology. Prices are $\mu_{t}^{j}$ for the two energy sources, and $w_{t}$ for labour. The price deflator is $\beta_{t}$, and shadow prices are $\widetilde{\lambda}_{t}$ for $\widetilde{Y}_{t}^{C}, \widetilde{\mu}_{t}^{j}$ for $\widetilde{Y}_{t}^{j}, \widetilde{w}_{t}$ for $\widetilde{L}_{t}, \widetilde{\tau}_{t}$ for $\widetilde{E} m_{t}, \tilde{\theta}_{t}$ for $\widetilde{Z}_{t}, \widetilde{\chi}_{t}$ for $\widetilde{E}_{t}, \varphi_{t}^{j}$ for $Q_{t}^{j}, \widetilde{\xi}_{t}^{j}$ for $\widetilde{M}_{t}^{j}$ and $\zeta_{t}^{j}$ and $\eta_{t}^{j}$ are the Lagrange variables of (36), and (37). The final good commodity balance is given by (1). The welfare level is defined by the welfare function (2) and consumer behaviour by the first order condition (3). Production of the final good is defined by production identities (5)-(12), and the first order conditions (25)-(34). Energy production is defined by production identities (16), (35), (36), and (37), and the first order conditions (38)-(42). Endogenous technological change is defined by (19) and (20). Finally, climate change is defined by (22) and (23).

As we have a vintage model, the flows one period before the first period, that is in period $t=0$, determine the flows of the old vintage in period $t=1$, and are exogenous to the model: $Y_{0}^{C}, I_{0}^{C}, I_{0}^{F}, I_{0}^{N}, M_{0}^{F}, M_{0}^{N}, X_{1}^{F}$ and $X_{1}^{N}$ have to be specified as input (or initiation) parameters at the start of the model simulation, as they result from investment decisions before period $t=1$.

For computational efficiency, we leave various variables out of the equilibrium, and calculate these variable in advance (ex-ante), or afterwards (ex-post). For example, labour is supplied inelastically, and is assumed to increase proportionally with population levels. The labour flow available for each new vintage $\widetilde{L}_{t}$ can, ex-ante, be calculated by (11). Consequently, we can leave the first order conditions for $L_{t}$ and $\widetilde{L}_{t},(27)$ and (31), out of the model, and calculate $w_{t}^{j}$ and $\widetilde{w}_{t}^{j}$ afterwards, when required. The technology variable $h_{t}^{j}$ is calculated afterwards by (20). That is, the equation is left out of the equilibrium equation set, and (35) and (38) are rewritten as:

$$
\begin{array}{ll}
\mathrm{G}^{j}\left(X_{t+1}^{j}\right)-\mathrm{G}^{j}\left(X_{t}^{j}\right)=Q_{t}^{j} & \left(\varphi_{t}^{j}, j=F, N\right) \\
\tilde{\mu}_{t}^{j} \tilde{Y}_{t}^{j}=\varphi_{t}^{j} Q_{t}^{j} & \left(\widetilde{Y}_{t}^{j}, j=F, N\right)
\end{array}
$$

respectively, where for notational convenience, we use the primitive of $\mathrm{g}^{j}($.$) , the function \mathrm{G}^{j}($. that is given by: ${ }^{14}$

$$
\mathrm{G}^{j}(X)=c^{j} X^{1-d^{j}}+X
$$

The variable $Y_{t}^{j}$ and its price $\mu_{t}^{j}(j=F, N)$ are also calculated afterwards omitting equation (10) and (26) out of the equilibrium equation set. This brings us to the full list of equilibrium equations:

${ }^{14}$ The function $\mathrm{g}^{j}($.$) is the first derivative of \mathrm{G}^{j}($.$) .$ 


\section{Welfare:}

$$
W=\sum_{t=1}^{\infty}(1+\rho)^{-t} L_{t} \ln \left(C_{t} / L_{t}\right)
$$

\section{Production and consumption:}

$$
\begin{array}{ll}
C_{t}+I_{t}^{C}+I_{t}^{F}+I_{t}^{N}+M_{t}^{F}+M_{t}^{N}=Y_{t}^{C} & \\
Y_{t}^{C}=(1-\delta) Y_{t-1}^{C}+\widetilde{Y}_{t}^{C} & \left(\tilde{\lambda}_{t}^{1}\right) \\
\widetilde{Y}_{t}^{C}=\left(\left(A_{t}^{1} \widetilde{Z}_{t}\right)^{(\gamma-1) / \gamma}+\left(A_{t}^{2} \widetilde{E}_{t}\right)^{(\gamma-1) / \gamma}\right)^{\gamma /(\gamma-1)} & \left(\tilde{\lambda}_{t}^{2}\right) \\
\widetilde{Z}_{t}=\left(I_{t-1}^{C}\right)^{\alpha}\left(\widetilde{L}_{t}\right)^{1-\alpha} & \left(\widetilde{\theta}_{t}\right) \\
\widetilde{E}_{t}=\left(\left(\widetilde{Y}_{t}^{F}\right)^{(\sigma-1) / \sigma}+\left(\widetilde{Y}_{t}^{N}\right)^{(\sigma-1) / \sigma}\right)^{\sigma /(\sigma-1)} & \left(\widetilde{\chi}_{t}\right) \\
X_{t+1}^{j}=X_{t}^{j}+\widetilde{Y}_{t}^{j} & (j=F, N) \\
\mathrm{G}^{j}\left(X_{t+1}^{j}\right)-\mathrm{G}^{j}\left(X_{t}^{j}\right)=Q_{t}^{j} & \left(\varphi_{t}^{j}, j=F, N\right. \\
Q_{t}^{j}=a^{j} I_{t-1}^{j} & \left(\zeta_{j, t} ; j=F, N\right) \\
Q_{t}^{j}=b^{j} \widetilde{M}_{t}^{j} & \left(\eta_{j, t} ; j=F, N\right) \\
M_{t}^{j}=(1-\delta) M_{t-1}^{j}+\widetilde{M}_{t}^{j} & \left(\xi_{j, t} ; j=F, N\right) \\
\widetilde{\xi}_{t}^{j}=(1-\delta) \beta_{t} \widetilde{\xi}_{t+1}^{j}+1 & \left(M_{t}^{j}, j=F, N\right)
\end{array}
$$

First order conditions:

$$
\begin{array}{ll}
\beta_{t}=\left(C_{t} / L_{t}\right) /\left((1+\rho)\left(C_{t+1} / L_{t+1}\right)\right) & \left(Y_{t}^{C}\right) \\
\tilde{\lambda}_{t}=(1-\delta) \beta_{t} \widetilde{\lambda}_{t+1}+1 & \left(E m_{t}\right) \\
\tau_{t}=\widetilde{\tau}_{t}-(1-\delta) \beta_{t} \widetilde{\tau}_{t+1} & \left(\widetilde{Z}_{t}\right) \\
\widetilde{\theta}_{t}=\widetilde{\lambda}_{t}^{2}\left(A_{t}^{1}\right)^{(\gamma-1) / \gamma}\left(\widetilde{Z}_{t} / \widetilde{Y}_{t}^{C}\right)^{-1 / \gamma} & \left(I_{t}^{C}\right) \\
1=\beta_{t} \widetilde{\theta}_{t+1} \alpha \widetilde{Z}_{t+1} / I_{t}^{C} & \left(\widetilde{E}_{t}\right) \\
\widetilde{\chi}_{t}=\widetilde{\lambda}_{t}^{2}\left(A_{t}^{2}\right)^{(\gamma-1) / \gamma}\left(\widetilde{E}_{t} / \widetilde{Y}_{t}^{C}\right)^{-1 / \gamma} & \left(\widetilde{Y}_{t}^{j} ; j=F\right) \\
\widetilde{\mu}_{t}^{j}+\varepsilon_{t}^{j} \widetilde{\tau}_{t}=\widetilde{\chi}_{t}\left(\widetilde{Y}_{t}^{j} / \widetilde{E}_{t}\right)^{-1 / \sigma} & \left(\widetilde{Y}_{t}^{j}, j=F, N\right) \\
\widetilde{\mu}_{t}^{j} \widetilde{Y}_{t}^{j}=\varphi_{t}^{j} Q_{t}^{j} & \left(Q_{t}^{j}, j=F, N\right) \\
\varphi_{t}^{j}=\zeta_{t}^{j}+\eta_{t}^{j} & \left(\widetilde{M}_{t}^{j}, j=F, N\right) \\
\widetilde{\xi}_{t}^{j}=b^{j} \eta_{t}^{j} & \left(I_{t-1}^{j}, j=F, N\right) \\
1=a^{j} \beta_{t} \zeta_{t+1}^{j} &
\end{array}
$$

Emissions and climate change:

$$
\begin{array}{ll}
\tilde{E} m_{t}=\varepsilon_{t}^{F} \tilde{Y}_{t}^{F} & \left(\widetilde{\tau}_{t}\right) \\
E m_{t}=(1-\delta) E m_{t-1}+\widetilde{E} m_{t} & \left(\widetilde{\tau}_{t}\right) \\
\operatorname{Atm}_{t+1}=\left(1-\delta^{M}\right) \operatorname{Atm}_{t}+\pi\left(E m_{t}+E m_{t}\right) & \\
\operatorname{Temp}_{t+1}=\left(1-\delta^{T}\right) \operatorname{Temp}_{t}+\delta^{T} \bar{T}{ }^{2} \ln \left(\text { Atm }_{t} / \operatorname{Atm}_{0}\right) &
\end{array}
$$

